\title{
Respiratory Syncytial Virus and Recurrent Wheeze in Healthy Preterm Infants
}

\author{
Maarten O. Blanken, M.D., Maroeska M. Rovers, Ph.D., Jorine M. Molenaar, M.D., \\ Pauline L. Winkler-Seinstra, M.Sc., Adam Meijer, Ph.D., Jan L.L. Kimpen, M.D., Ph.D., \\ and Louis Bont, M.D., Ph.D., for the Dutch RSV Neonatal Network
}

ABSTRACT

\begin{abstract}
BACKGROUND
Respiratory syncytial virus (RSV) infection is associated with subsequent recurrent wheeze. Observational studies cannot determine whether RSV infection is the cause of recurrent wheeze or the first indication of preexistent pulmonary vulnerability in preterm infants. The monoclonal antibody palivizumab has shown efficacy in preventing severe RSV infection in high-risk infants.
\end{abstract}

\section{METHODS}

In the double-blind, placebo-controlled MAKI trial, we randomly assigned 429 otherwise healthy preterm infants born at a gestational age of 33 to 35 weeks to receive either monthly palivizumab injections (214 infants) or placebo (215 infants) during the RSV season. The prespecified primary outcome was the total number of parentreported wheezing days in the first year of life. Nasopharyngeal swabs were taken during respiratory episodes for viral analysis.

\section{RESULTS}

Palivizumab treatment resulted in a relative reduction of $61 \%$ (95\% confidence interval, 56 to 65) in the total number of wheezing days during the first year of life (930 of 53,075 days in the RSV-prevention group [1.8\%] vs. 2309 of 51,726 days [4.5\%] in the placebo group). During this time, the proportion of infants with recurrent wheeze was 10 percentage points lower in patients treated with palivizumab $(11 \%$ vs. $21 \%, \mathrm{P}=0.01)$.

\section{CONCLUSIONS}

In otherwise healthy preterm infants, palivizumab treatment resulted in a significant reduction in wheezing days during the first year of life, even after the end of treatment. These findings implicate RSV infection as an important mechanism of recurrent wheeze during the first year of life in such infants. (Funded by Abbott Laboratories and by the Netherlands Organization for Health Research and Development; MAKI Controlled Clinical Trials number, ISRCTN73641710.)
From the Division of Pediatric Immunology and Infectious Diseases, University Medical Center Utrecht, Utrecht (M.O.B., J.M.M., P.L.W.-S., J.L.L.K., L.B.), the Departments of Operating Rooms and Epidemiology, Biostatistics and HTA (Health Technology Assessment), Julius Center for Health Sciences and Primary Care, University Medical Center, Utrecht, and Radboud University Nijmegen Medical Center, Nijmegen (M.M.R.), and the Department of Virology, National Institute for Public Health and the Environment, Bilthoven (A.M.) - all in the Netherlands. Address reprint requests to Dr. Bont at University Medical Center Utrecht, Pediatric Immunology and Infectious Diseases, P.O. Box 85090, 3508 AB Utrecht, the Netherlands, oratl.bont@umcutrecht.nl.

This article was last updated on July 15 , 2016, at NEJM.org.

N Engl J Med 2013;368:1791-9. DOI: 10.1056/NEJMoal211917

Copyright (؟) 2013 Massachusetts Medical Society. 
LLNESS OF THE LOWER RESPIRATORY TRACT that is caused by respiratory syncytial virus (RSV) is the most common cause of hospital admission in the winter season during the first year of life. ${ }^{1}$ Severe RSV bronchiolitis has been associated with an increase in subsequent rates of early wheezing, ${ }^{2,3}$ asthma, and possibly allergic sensitization later in life. ${ }^{4-7}$ Early childhood wheeze after RSV infection has a high prevalence, influences quality of life, and generates substantial health care costs. ${ }^{8-11}$

The pathogenesis of recurrent wheeze after RSV infection is still poorly understood. Gern and Busse distinguished two nonexclusive relationships between RSV infection and wheezing. ${ }^{12}$ First, RSV bronchiolitis may interfere with normal lung development or immune maturation and subsequently cause recurrent episodes of wheezing. Second, RSV infection may be the earliest stimulus for wheezing in children who are predisposed to wheeze by genetic susceptibility or preexisting abnormal lung function at birth. A birth cohort study provided limited evidence for a causal relationship between RSV and recurrent wheeze, since the timing of birth in relationship to the annual winter RSV peak predicted the risk of recurrent wheeze. ${ }^{13}$ So far, the potential causal role of RSV infection in the development of recurrent wheeze is debated, but strong empirical evidence is lacking. ${ }^{14,15} \mathrm{Wu}$ and Hartert therefore concluded that a randomized clinical trial using RSV prophylaxis was warranted to confirm a causal relationship between RSV infection and recurrent wheeze. ${ }^{16}$

We performed the multicenter, double-blind, randomized, placebo-controlled MAKI trial to investigate the potential causal role of RSV infection in the pathogenesis of wheezing illness during the first year of life, using the commercially available monoclonal antibody palivizumab (Synagis, MedImmune) against RSV.

\section{METHODS}

\section{PATIENTS}

From April 2008 through December 2010, we enrolled preterm infants (gestational age, 33 to 35 weeks) in pediatric departments of one university and 15 regional hospitals in the Netherlands. All the infants were otherwise healthy and 6 months of age or younger at the start of the RSV season. We excluded infants with congeni- tal heart disease, bronchopulmonary dysplasia, Down's syndrome, ${ }^{17}$ or other serious congenital disorders and infants who required mechanical ventilation at birth, who were treated with surfactant, or who had physician-diagnosed wheeze before the start of the RSV season.

Parents provided written informed consent for study participation. The study was conducted according to the principles of the Declaration of Helsinki (version 2000). A yearly monitoring program that followed current Good Clinical Practice guidelines was run routinely.

\section{ETHICAL ISSUES}

Palivizumab is registered but not reimbursed in the Netherlands for preterm infants born at a gestational age of 33 to 35 weeks. Because RSV immunoprophylaxis is effective in preventing RSV lower respiratory tract illness in such preterm infants, ${ }^{18}$ our study was marked as a therapeutic study. The institutional review board at the University Medical Center Utrecht decided that the $50 \%$ chance of benefit of RSV prevention with palivizumab outweighed the risk of moderate side effects caused by the intramuscular administration of placebo and the burden of participating in this trial. The protocol was reviewed and approved by the institutional review board at the University Medical Center Utrecht and at each participating hospital.

\section{RANDOMIZATION}

Eligible infants were randomly assigned in a 1:1 ratio to receive either palivizumab (at a dose of $15 \mathrm{mg}$ per kilogram of body weight) or placebo during the winter season (details are provided in the Supplementary Appendix, available with the full text of this article at NEJM.org). The blinding of study-group assignment was performed with a randomization list that used a permuted-block design, which was generated by an independent pharmacist before the start of the trial. The randomization was stratified according to gestational age. Blinding was achieved with the use of a placebo matching the reconstituted palivizumab solution. The researchers who received the logs and performed the analyses and the parents were unaware of study-group assignments until 1 year of follow-up was completed for all participants. The research nurses who administered the study drugs were aware of study-group assignments because it was not feasible to prepare and administer the 
treatment in a blinded fashion within 3 hours after reconstitution. The research nurses were trained to reveal no knowledge of the randomization to parents and were not involved in the reporting of data analyses. The research nurses worked with standard operating procedures and were carefully instructed to prevent possible unblinding.

\section{STUDY OUTCOMES AND FOLLOW-UP}

The primary outcome was number of parentreported wheezing days in the first year of life. Using methods identical to those used in our previous trial, parents recorded airway symptoms, doctor visits, and the use of airway drugs in a daily log until their infant was 1 year of age. ${ }^{19,20}$ Instructions for completing the log were given during the first home visit, and compliance was checked at each subsequent home visit.

Secondary outcomes were the number of days with bronchodilator use, the number of RSV infections confirmed by means of a nasopharyngeal swab positive for RSV RNA with or without medical attention, the number of hospitalizations for laboratory-proven RSV infection, the number of wheezing episodes, and the prevalence of recurrent wheeze. Medical attention was defined as a visit to either a general practitioner or a hospital. A wheezing episode was defined as a respiratory episode with wheezing on more than 1 day. The interval between two episodes was defined as a period of at least 7 days without respiratory symptoms. Recurrent wheeze was defined as three or more episodes of wheezing during the first year of life. A family history of atopy was defined as a physician diagnosis of asthma, hay fever, or eczema in at least one of the parents.

\section{LABORATORY TESTS AND FOLLOW-UP}

We defined the post-prophylaxis period as the follow-up from 2 months after the last treatment administration (three half-lives of palivizumab) up to the age of 1 year. In case of respiratory symptoms, primary care was left to the general practitioner.

Parents were instructed to take a nasopharyngeal swab in case of the occurrence of respiratory symptoms with involvement of the upper or lower respiratory tract lasting more than 1 day. The swab was transported in a viral transport medium by regular mail to the laboratory and stored at $-80^{\circ} \mathrm{C}$ until polymerase-chain-reaction (PCR) assays were performed. The presence of
RSV RNA was determined by multiplex real-time reverse-transcriptase-PCR with the use of previously published primers and probes for RSV- $\mathrm{B}^{21}$ and primers and probes for RSV-A that were developed in-house (details are provided in the Supplementary Appendix).

We determined the presence of 16 respiratory viruses and 4 respiratory bacteria using the RespiFinder SMART 22 assay (PathoFinder). ${ }^{22}$ Positive results on testing for rhinovirus or enterovirus are referred to as rhinovirus infection. All hospitalizations were evaluated, and any deaths were regarded as serious adverse events. Local injection-site reactions and physician visits for nonrespiratory symptoms were not recorded.

\section{STUDY OVERSIGHT}

The academic authors designed and conducted the study without input from the study sponsor (Abbott Laboratories, which markets palivizumab) other than financial support and donation of the palivizumab. All authors vouch for the accuracy and completeness of the data reported and for the fidelity of this report to the study protocol, available at NEJM.org.

\section{STATISTICAL ANALYSIS}

The sample-size calculation was based on a clinically relevant between-group difference of a mean $( \pm$ SD) of $5 \pm 15$ wheezing days during the first year of life. ${ }^{20,23,24}$ The predefined target of 226 infants per study group provided a power of at least $90 \%$ to detect a clinically relevant difference in wheezing days with the use of an alpha level of 0.05. Since a typical Poisson distribution for probability arose, we used Poisson regression analysis to study potential differences in the number of days with wheeze. ${ }^{20}$ Percentages and associated $95 \%$ confidence intervals of infants with wheezing or recurrent wheeze episodes were calculated. We used chi-square tests, Student's t-tests, and Mann-Whitney U tests to evaluate differences in percentages, mean values, and median values between the two study groups. All analyses were performed on an intention-to-treat basis. No imputation of missing data was performed, since the overall amount of missing data was less than $10 \%$. Post hoc subgroup analyses were performed to assess wheezing days in subgroups of children with a family history of atopy or asthma. All statistical analyses were performed with SPSS software, version 20.0. 


\section{RESULTS}

\section{PATIENTS}

Of 1550 late preterm infants (gestational age, 33 to 35 weeks) who underwent screening, 429 were enrolled in the study (Fig. 1A). The median day of birth was August 22 for infants who were enrolled in the study, as compared with a median day of birth of August 5 for infants who were not enrolled. The two study groups were well balanced on the basis of inclusion year, gestational age, and birth month. Birth weight, family history of atopy, presence of siblings, and other baseline characteristics were similar, except for sex $(58 \%$ male infants in the RSV-prevention group vs. $44 \%$ in the placebo group) (Table S1 in the Supplementary Appendix). By design, only children with no previous wheezing symptoms were enrolled.

A median number of 4 injections during the RSV season were administered to infants in the RSV-prevention group (range, 1 to 5) and the placebo group (range, 2 to 5). In the RSV-prevention group, $95 \%$ of scheduled injections and $89 \%$ of follow-up of daily logs were completed, as compared with rates of $92 \%$ and $88 \%$, respectively, in the placebo group. The median follow-up duration was 10 months (range, 0 to 12 ) in the two study groups.

\section{RSV INFECTION}

We studied the occurrence and severity of RSV infection to confirm the efficacy of RSV immunoprophylaxis in our study population. We confirmed that infants who were treated with palivizumab had a lower incidence of RSV-related hospitalization than those treated with placebo $(0.9 \%$ vs. $5.1 \%$, $\mathrm{P}=0.01) .{ }^{18}$ The infants who were treated with palivizumab also had a lower incidence of medically attended nonhospitalized RSV infection (Table 1).

\section{PRIMARY AND SECONDARY OUTCOMES}

The number of days with parent-reported wheeze was lower in the RSV-prevention group than in the placebo group (Table 2 and Fig. 2). This result was consistent for all 3 study years and independent of the number of injections of palivizumab or placebo. There was an absolute reduction of 2.7 percentage points in rates of wheezing in the RSV-prevention group versus the placebo group ( 930 of 53,075 days [1.8\%] and 2309 of 51,726 days [4.5\%], respectively), for a relative reduction of $61 \%$ ( $95 \%$ confidence interval [CI], 56 to 65 ).
The effect of RSV prevention on the number of wheezing days persisted during the post-prophylaxis period (i.e., starting at 2 months after the last injection), for a relative reduction of $73 \%$ (95\% CI, 66 to 80 ). Similarly, there was a decrease in the number of wheezing days outside the RSV season in the RSV-prevention group (Table 2). Among children with any proven RSV infection, there was no significant between-group difference in the incidence of wheezing ( $23 \%$ in the RSV-prevention group and $30 \%$ in the placebo group) or in the mean number of wheezing days during the first year of life (8.2 days in the RSV-prevention group and 16 days in the placebo group). We did not detect RSV reinfection in either group.

The proportion of infants with recurrent wheezing was lower in the RSV-prevention group than in the placebo group $(11.2 \%$ vs. $20.9 \%$, $\mathrm{P}=0.005$ ) (Table 3). Similarly, the proportion of infants using bronchodilators was lower in the RSV-prevention group than in the placebo group ( $13 \%$ vs. $23 \%, \mathrm{P}<0.001)$. The effect of RSV prevention on the total number of wheezing days was not significantly different $(\mathrm{P}=0.89)$ in children without a family history of atopy (72\% reduction; 95\% CI, 65 to 79), as compared with those with a family history of atopy (54\% reduction; $95 \%$ CI, 47 to 60 ). A similar effect of RSV prevention was seen in children without and with parental asthma (68\% reduction [ $95 \%$ CI, 62 to 73] vs. $35 \%$ reduction [ $95 \%$ CI, 23 to 47]). The total numbers of respiratory episodes were similar in the two study groups. However, we found more coinfections during nonwheezing episodes in the RSV-prevention group than in the placebo group (101 of 236 swabs [43\%] vs. 63 of 197 swabs [32\%], $\mathrm{P}=0.02$ ) (Fig. $1 \mathrm{~B}$ ).

\section{ADVERSE EVENTS}

The proportion of patients with serious adverse events was lower in the RSV-prevention group than in the placebo group. We observed 32 hospitalizations in 27 children (12.6\%) in the RSVprevention group, as compared with 52 hospitalizations in 47 children $(21.9 \%)$ in the placebo group $(\mathrm{P}=0.04)$. Reasons for hospitalization in the RSV-prevention group were RSV infection (in 2 patients), other respiratory tract illness (in 6), gastroenteritis (in 6), surgery (in 6), failure to thrive (in 6), and other reasons (in 6). Reasons for hospitalization in the placebo group were RSV 


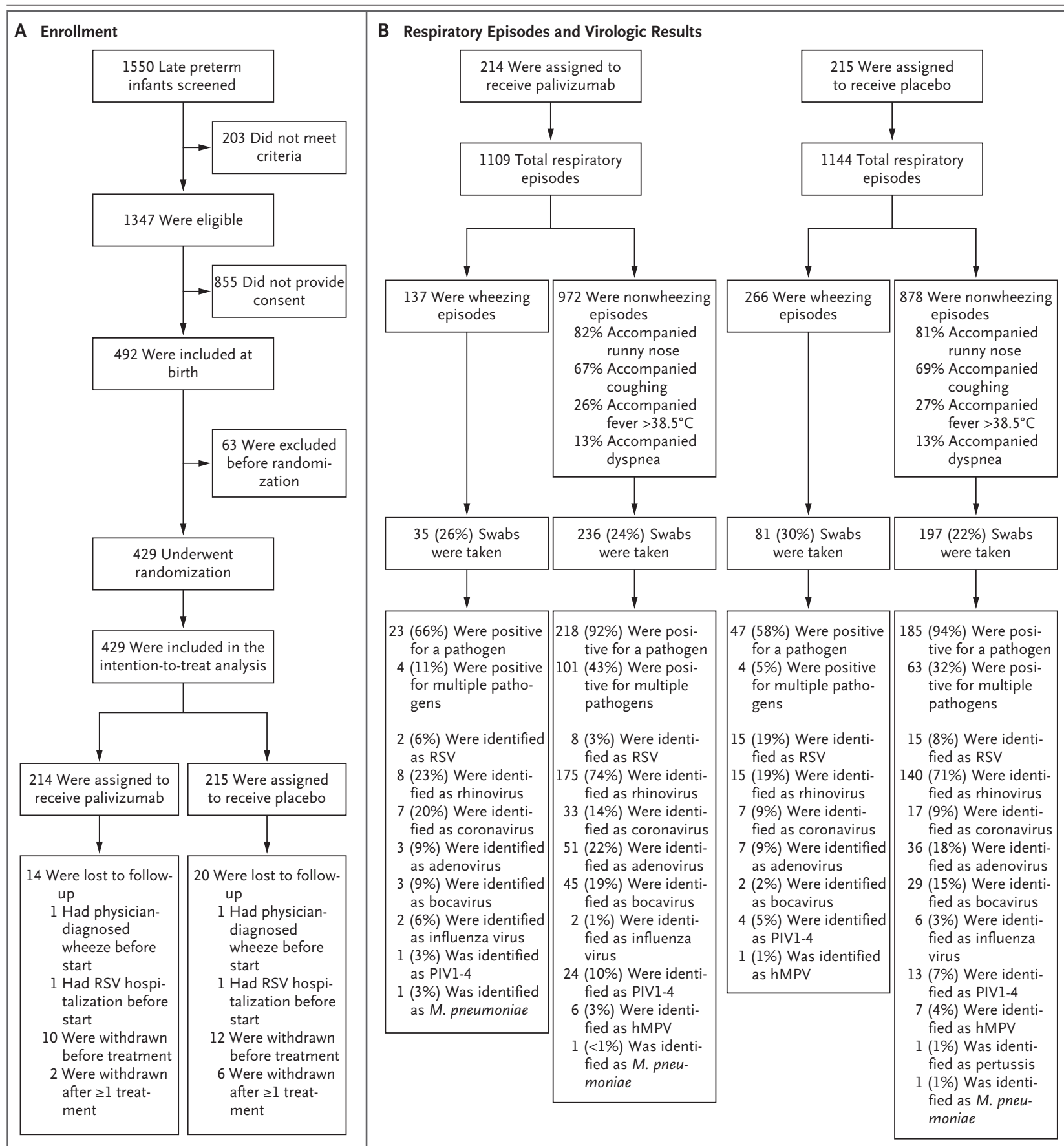

Figure 1. Enrollment, Number of Respiratory Episodes, and Results of Virologic Analyses.

Panel A shows enrollment and study outcomes for the 429 infants who were included in the intention-to-treat analysis. Panel B shows the total number of respiratory symptoms, which were based on parent records. A respiratory episode was defined as an episode of at least 2 consecutive days of upper or lower respiratory symptoms. Parents were instructed to take a nasopharyngeal swab on the second day of every respiratory episode. Respiratory syncytial virus (RSV) was detected with the use of in-house real-time reverse-transcriptasepolymerase-chain-reaction assays, and the RespiFinder SMART 22 assay was used for the detection of adenovirus, bocavirus, Bordetella pertussis, Chlamydia pneumoniae, coronavirus (229E, HKU1, NL63, and OC43), human metapneumovirus (hMPV), influenza virus type A, influenza virus $\mathrm{A}(\mathrm{H} 1 \mathrm{~N} 1)$ pdm09, influenza virus type $\mathrm{B}$ (influenza virus), Legionella pneumophila, Mycoplasma pneumoniae, parainfluenza virus types 1 through 4 (PIVI-4), RSV types A and B (RSV), and rhinovirus or enterovirus (rhinovirus). 
infection (in 11 patients), other respiratory tract illness (in 6), gastroenteritis (in 10), surgery (in 13), failure to thrive (in 8), and other reasons (in 4). There were no deaths.

\section{DISCUSSION}

In this proof-of-concept study, treatment with a monoclonal antibody for RSV prevention in late preterm infants greatly reduced the number of parent-reported wheezing days during the first year of life, even after the end of therapy and outside the RSV season. RSV prevention reduced wheezing, but wheezing was not eliminated. RSV prevention was associated with a relative reduction of $61 \%$ in the number of wheezing days, a finding that shows that RSV infection is an im- portant mechanism in the pathogenesis of wheezing morbidity in this specific population.

Our results are in line with other studies that acknowledge the relationship between RSV bronchiolitis and recurrent wheeze. ${ }^{4,7,9,25-27} \mathrm{Wu}$ et al. ${ }^{13}$ found that the timing of birth date with respect to the peak of the winter bronchiolitis season was related to the risk of asthma. These findings suggest that asthma is most likely to develop in infants who are at highest risk for severe viral bronchiolitis. However, other studies have argued against RSV as the cause of pulmonary damage and subsequent early childhood wheezing. ${ }^{2}$ The role of RSV in the development of asthma remains controversial, and our data cannot provide evidence in this discussion. ${ }^{28}$ A previous nonrandomized trial suggested that the prevention

\begin{tabular}{|c|c|c|c|c|c|}
\hline \multirow[t]{2}{*}{ Variable } & $\begin{array}{l}\text { Palivizumab } \\
(\mathrm{N}=214)\end{array}$ & $\begin{array}{l}\text { Placebo } \\
(\mathrm{N}=215)\end{array}$ & $\begin{array}{c}\text { Absolute Risk } \\
\text { Reduction } †\end{array}$ & 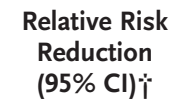 & P Value \\
\hline & \multicolumn{2}{|c|}{ no. (\%) } & percentage points & $\%$ & \\
\hline Total RSV infection & $10(4.7)$ & $30(14.0)$ & 9.3 & 67 (27 to 107$)$ & 0.001 \\
\hline Hospitalization for RSV infection & $2(0.9)$ & $11(5.1)$ & 4.2 & 82 (18 to 157$)$ & 0.01 \\
\hline $\begin{array}{l}\text { Medically attended RSV infection without } \\
\text { hospitalization }\end{array}$ & $2(0.9)$ & $10(4.7)$ & 3.7 & $80(11$ to 161$)$ & 0.02 \\
\hline RSV infection without medical attention & $6(2.8)$ & $9(4.2)$ & 1.4 & $33(-56$ to 126$)$ & 0.40 \\
\hline
\end{tabular}

* Medical attention was registered during the home visits and reported by parents on the daily log.

$\uparrow$ The absolute and relative values for risk reduction are for the palivizumab group as compared with the placebo group.

Table 2. Days with Wheezing in the First Year of Life.*

\begin{tabular}{|c|c|c|c|c|c|c|c|c|}
\hline \multirow[t]{3}{*}{ Variable } & \multicolumn{3}{|c|}{ Palivizumab ( $N=214$ ) } & \multicolumn{3}{|c|}{ Placebo ( $N=215$ ) } & \multirow{3}{*}{$\begin{array}{l}\text { Absolute } \\
\text { Reduction'̄ं } \\
\text { no. of } \\
\text { symptom days }\end{array}$} & \multirow{3}{*}{$\begin{array}{c}\text { Relative Risk } \\
\text { Reduction }(95 \% \mathrm{Cl}) \uparrow \\
\%\end{array}$} \\
\hline & $\begin{array}{l}\text { Total Log } \\
\text { Days }\end{array}$ & $\begin{array}{c}\text { Total } \\
\text { Symptom } \\
\text { Days }\end{array}$ & $\begin{array}{l}\text { Incidence } \\
\text { per Day }\end{array}$ & $\begin{array}{c}\text { Total Log } \\
\text { Days }\end{array}$ & $\begin{array}{l}\text { Total } \\
\text { Symptom } \\
\text { Days }\end{array}$ & $\begin{array}{l}\text { Incidence } \\
\text { per Day }\end{array}$ & & \\
\hline & \multicolumn{2}{|c|}{ no. } & $\%$ & \multicolumn{2}{|c|}{ no. } & $\%$ & & \\
\hline \multicolumn{9}{|l|}{ Days with wheezing } \\
\hline First year of life & 53,075 & 930 & 1.8 & 51,726 & 2309 & 4.5 & 1379 & $61(56-65)$ \\
\hline$<2$ mo after prophylaxis & 28,455 & 666 & 2.3 & 28,220 & 1382 & 4.9 & 716 & $52(46-59)$ \\
\hline$\geq 2$ mo after prophylaxis & 24,620 & 264 & 1.1 & 23,506 & 927 & 3.9 & 663 & $73(66-80)$ \\
\hline During RSV season & 26,176 & 646 & 2.5 & 26,081 & 1348 & 5.2 & 702 & $52(46-59)$ \\
\hline Outside RSV season & 26,899 & 284 & 1.1 & 25,645 & 961 & 3.7 & 677 & $73(66-80)$ \\
\hline
\end{tabular}

* The incidence of wheezing was calculated as the number of days with parent-reported airway symptoms divided by the number of log days during follow-up. $\mathrm{P}<0.001$ for all comparisons except $\mathrm{P}=0.006$ for the category of less than 2 months after the end of prophylaxis.

$\dagger$ The values for absolute reduction and relative risk reduction are for the palivizumab group as compared with the placebo group.

The RSV season was defined as October 1 to March 31. 
of lower respiratory tract illness caused by RSV reduced subsequent recurrent wheeze in infants without a family history of atopy but showed no effect in infants with a family history of atopy. ${ }^{29,30}$ We found that RSV prevention was associated with reduced wheezing in the first year of life, regardless of whether there was a family history of atopy. Our study underlines the important role that RSV plays in the pathogenesis of recurrent wheeze. We hypothesize that RSV primarily causes direct pulmonary epithelial damage and local immunologic alterations in the lungs, leading to longterm airway hyperresponsiveness and wheezing.

A study in mice showed that RSV causes persistent airway hyperresponsiveness, chronic lung inflammation, and histopathological abnormalities. ${ }^{31,32}$ Altered immune-response patterns have been described after RSV infection. Studies in mice and humans have suggested that local production of interleukin-10 during RSV infection is a key mechanism in the development of recurrent wheeze and airway hyperresponsiveness, although mechanisms independent of interleukin- 10 have also been described. ${ }^{19,33-36}$ We believe that alterations to the pulmonary environment and immunologic phenotype caused by RSV infection in early life eventually lead to long-term remodeling of the pulmonary system and hyperresponsiveness to respiratory viruses and nonspecific stimuli.

In our study, the numbers of respiratory episodes were similar in the two study groups. However, in the RSV-prevention group, we found more coinfections than in the placebo group. Previous studies have not addressed the effect of palivizumab on the acquisition or clearance of respiratory viruses other than RSV. RSV bronchiolitis is followed by a robust inflammatory response in the airways, which may persist for more than

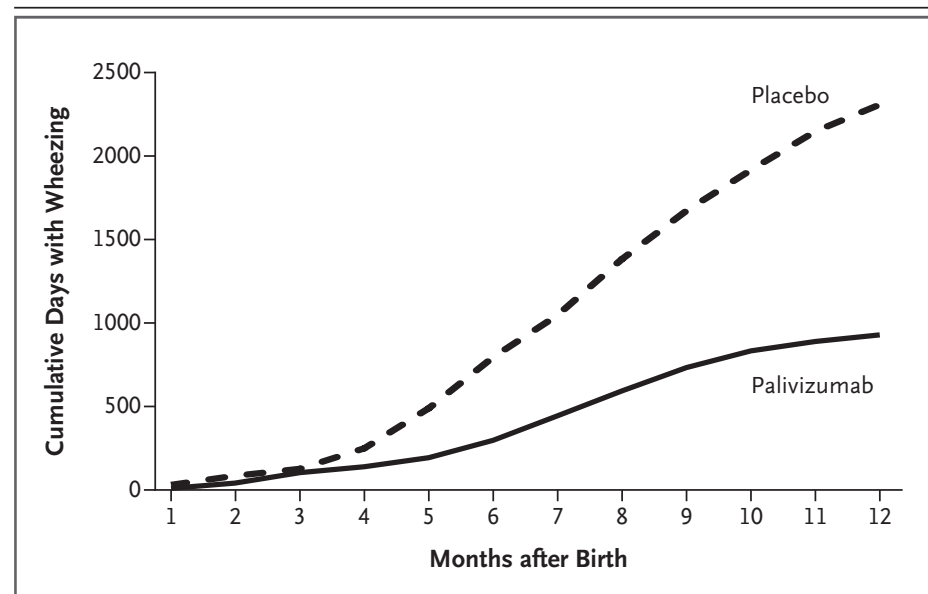

Figure 2. Cumulative Wheezing Days for 429 Preterm Infants during the First Year of Life.

$\mathrm{P}<0.001$ for the comparison between palivizumab and placebo with the use of Poisson regression.

1 month. ${ }^{37}$ We speculate that this inflammatory response, including production of interferons, transiently protects against subsequent viral infection, resulting in fewer coinfections..$^{38,39}$ More research is needed to unravel how respiratory viruses interact at the mucosal level.

The major strength of our study is the randomized design, which precludes bias from selection or confounding and which subsequently provided unbiased and conclusive evidence regarding the mechanism of RSV infection in the pathogenesis of infant wheezing. Some potential limitations should also be discussed. First, parents with an atopic history may have been more likely to participate in the study. However, since the stratified results did not differ between infants of parents with and those without an atopic history, our conclusions are generalizable. Second, although nasopharyngeal swabs were ob-

\begin{tabular}{|c|c|c|c|c|}
\hline Variable & $\begin{array}{l}\text { Palivizumab } \\
(\mathrm{N}=214)\end{array}$ & $\begin{array}{l}\text { Placebo } \\
(\mathrm{N}=215)\end{array}$ & $\begin{array}{l}\text { Absolute } \\
\text { Reduction't }\end{array}$ & $\begin{array}{c}\text { Relative Risk } \\
\text { Reduction }(95 \% \mathrm{Cl}) \dagger\end{array}$ \\
\hline Any wheezing - no. of infants (\%) & $66(30.8)$ & $101(47.0)$ & 16.2 & $34(14-53)$ \\
\hline Wheezing episodes — no. & 137 & 266 & 129 & $48(32-62)$ \\
\hline Recurrent wheezing - no. of infants (\%) & $24(11.2)$ & $45(20.9)$ & 9.7 & $47(14-80)$ \\
\hline
\end{tabular}

* Any wheezing was defined as at least one episode of wheezing during the first year of life. A wheezing episode was defined as a respiratory episode with wheezing on more than 1 day. Recurrent wheezing was defined as three or more episodes of wheezing during the first year of life. $\mathrm{P}<0.001$ for the between-group comparisons for any wheezing and wheezing episodes and $\mathrm{P}=0.005$ for recurrent wheezing.

$\uparrow$ The values for absolute reduction are percentage points, and the values for relative risk reduction are numbers of episodes. 
tained by parents to increase compliance of sampling, ${ }^{40}$ swabs were obtained in approximately $30 \%$ of all respiratory episodes. This is similar to the range of percentages (24 to $43 \%$ ) obtained in a study with a similar approach to parental swab collection. ${ }^{40,41}$ Consequently, we may underestimate the incidence of RSV infection. However, since the trial was double-blind and randomized, we do not believe this factor had an effect on the overall conclusions. Third, preterm infants are at higher risk for recurrent episodes of wheezing than are term infants. ${ }^{42}$ Therefore, we do not know whether our results can be generalized to healthy term infants. Fourth, we had to rely on parent-reported morbidity data, since no objective measure of wheezing was available. Identifying wheezing is problematic even for trained clinicians. ${ }^{43,44}$ However, since the parents were unaware of study-group assignments, we believe that any misclassification of wheezing was random in the two groups.

In summary, we have shown that the administration of palivizumab for RSV prevention reduced the total number of wheezing days in the first year of life among preterm infants with a gestational age of 33 to 35 weeks. The post- prophylaxis effect of RSV prevention on wheezing illness is evidence that RSV infection is an important mechanism in the pathogenesis of wheezing during the first year of life among late preterm infants.

Supported by an unrestricted grant from Abbott Laboratories and by a grant from the Netherlands Organization for Health Research and Development (NWO-AGIKO grant 920-035-89, to Dr. Blanken).

Disclosure forms provided by the authors are available with the full text of this article at NEJM.org.

We thank Loes Nibbelke and Shireen Jenny for their assistance in recruiting children, data collection, and virologic analyses; the children and their families who participated in the trial; and all nurses, nurse practitioners, supporting staff, and pediatricians in the hospitals of the Dutch RSV Neonatal Network who collaborated in the study: M.A. Verboon-Maciolek, M.D., Ph.D. (University Medical Center, Utrecht); W.J. de Waal, M.D., Ph.D. (Diakonessenhuis, Utrecht); J.A. Schipper, M.D., Ph.D. (St. Antonius Hospital, Nieuwegein); J.H. de Bie, M.D. (Zuwe Hofpoort Hospital, Woerden); C.B. Meijssen, M.D. (Meander Medical Center, Amersfoort); J.G. van Enk, M.D., Ph.D. (Hospital Gelderse, Vallei Ede); A. Zlotkowski, M.D. (Hospital Rivierenland, Tiel); R.A. Bruinsma, M.D. (Gelre Hospital, Apeldoorn); C.E. CrijnsKoers, M.D. (Tergooi Hospitals, Blaricum); R.P.H. Lubbers, M.D. (Rivas Beatrix Hospitals, Gorkum); A.C.M. Dassel, M.D., Ph.D. (Deventer Hospital, Deventer); C. Aleman, M.D. (Ikazia Hospital, Rotterdam); C.M.M.L. Bontemps, M.D. (St. Jansdal Hospital, Harderwijk); C.J. Miedema, M.D. (Catharina Hospital, Eindhoven); E.A. Smit-Kleinlugtenbeld, M.D. (Albert Schweitzer Hospital, Dordrecht); and R. van Gent, M.D., Ph.D. (Maxima Medical Center, Veldhoven).

\section{REFERENCES}

1. Hall CB, Weinberg GA, Iwane MK, et al. The burden of respiratory syncytial virus infection in young children. $\mathrm{N}$ Engl $\mathrm{J}$ Med 2009;360:588-98.

2. Stensballe LG, Simonsen JB, Thomsen $\mathrm{SF}$, et al. The causal direction in the association between respiratory syncytial virus hospitalization and asthma. J Allergy Clin Immunol 2009;123:131-7.

3. Carroll KN, Wu P, Gebretsadik T, et al. Season of infant bronchiolitis and estimates of subsequent risk and burden of early childhood asthma. J Allergy Clin Immunol 2009;123:964-6.

4. Henderson J, Hilliard TN, Sherriff A, Stalker D, Al SN, Thomas HM. Hospitalization for RSV bronchiolitis before 12 months of age and subsequent asthma, atopy and wheeze: a longitudinal birth cohort study. Pediatr Allergy Immunol 2005;16:386-92.

5. Bacharier LB, Cohen R, Schweiger T, et al. Determinants of asthma after severe respiratory syncytial virus bronchiolitis. J Allergy Clin Immunol 2012;130:91-100. 6. Stein RT, Sherrill D, Morgan WJ, et al. Respiratory syncytial virus in early life and risk of wheeze and allergy by age 13 years. Lancet 1999;354:541-5.

7. Sigurs N, Aljassim F, Kjellman B, et al. Asthma and allergy patterns over 18 years after severe RSV bronchiolitis in the first year of life. Thorax 2010;65:1045-52

8. Kuehni CE, Davis A, Brooke AM, Silverman M. Are all wheezing disorders in very young (preschool) children increasing in prevalence? Lancet 2001;357: 1821-5.

9. Bont L, Aalderen WM, Kimpen JL. Long-term consequences of respiratory syncytial virus (RSV) bronchiolitis. Paediatr Respir Rev 2000;1:221-7.

10. Bont L, Steijn M, Van Aalderen WM, Kimpen JL. Impact of wheezing after respiratory syncytial virus infection on health-related quality of life. Pediatr Infect Dis J 2004;23:414-7.

11. Miedema CJ, Kors AW, Tjon ATW Kimpen JL. Medical consumption and socioeconomic effects of infection with respiratory syncytial virus in The Netherlands. Pediatr Infect Dis J 2001;20:160-3.

12. Gern JE, Busse WW. Relationship of viral infections to wheezing illnesses and asthma. Nat Rev Immunol 2002;2:132-8.

13. Wu P, Dupont WD, Griffin MR, et al. Evidence of a causal role of winter virus infection during infancy in early childhood asthma. Am J Respir Crit Care Med 2008;178:1123-9.

14. Edwards MR, Bartlett NW, Hussell T, Openshaw P, Johnston SL. The microbiol- ogy of asthma. Nat Rev Microbiol 2012; 10:459-71.

15. Martinez FD. Respiratory syncytial virus bronchiolitis and the pathogenesis of childhood asthma. Pediatr Infect Dis J 2003;22:2 Suppl:S76-S82.

16. Wu P, Hartert TV. Evidence for a causal relationship between respiratory syncytial virus infection and asthma. Expert Rev Anti Infect Ther 2011;9:731-45. 17. Bloemers BL, van Furth AM, Weijerman $\mathrm{ME}$, et al. Down syndrome: a novel risk factor for respiratory syncytial virus bronchiolitis - a prospective birth-cohort study. Pediatrics 2007;120(4):e1076-e1081. 18. IMpact-RSV Study Group. Palivizumab, a humanized respiratory syncytial virus monoclonal antibody, reduces hospitalization from respiratory syncytial virus infection in high-risk infants. Pediatrics 1998;102:531-7.

19. Bont L, Heijnen CJ, Kavelaars A, et al. Monocyte IL-10 production during respiratory syncytial virus bronchiolitis is associated with recurrent wheezing in a one-year follow-up study. Am J Respir Crit Care Med 2000;161:1518-23.

20. Ermers MJ, Rovers MM, van Woensel JB, Kimpen JL, Bont LJ. The effect of high dose inhaled corticosteroids on wheeze in infants after respiratory syncytial virus 
infection: randomised double blind placebo controlled trial. BMJ 2009;338:b897. 21. Hu A, Colella M, Tam JS, Rappaport $\mathrm{R}$, Cheng SM. Simultaneous detection, subgrouping, and quantitation of respiratory syncytial virus A and B by real-time PCR. J Clin Microbiol 2003;41:149-54

22. Loens K, van Loon AM, Coenjaerts F, et al. Performance of different mono- and multiplex nucleic acid amplification tests on a multipathogen external quality assessment panel. J Clin Microbiol 2012;50: 977-87.

23. Bont L, Van Aalderen WM, Versteegh $\mathrm{J}$, et al. Airflow limitation during respiratory syncytial virus lower respiratory tract infection predicts recurrent wheezing. Pediatr Infect Dis J 2001;20:277-82.

24. Bont L, Steijn M, Van Aalderen WM, et al. Seasonality of long term wheezing following respiratory syncytial virus lower respiratory tract infection. Thorax 2004; 59:512-6.

25. Hall CB, Hall WJ, Gala CL, MaGill FB, Leddy JP. Long-term prospective study in children after respiratory syncytial virus infection. J Pediatr 1984;105:358-64.

26. Pullan CR, Hey EN. Wheezing, asth$\mathrm{ma}$, and pulmonary dysfunction 10 years after infection with respiratory syncytial virus in infancy. Br Med J (Clin Res Ed) 1982;284:1665-9.

27. Eisen AH, Bacal HL. The relationship of acute bronchiolitis to bronchial asthma: a 4-to-14-year follow-up. Pediatrics 1963;31:859-61.

28. Welliver RC. RSV and chronic asthma. Lancet 1995;346:789-90.

29. Simões EA, Groothuis JR, CarbonellEstrany X, et al. Palivizumab prophylaxis, respiratory syncytial virus, and subse- quent recurrent wheezing. J Pediatr 2007; 151:34-42.

30. Simões EA, Carbonell-Estrany X, Rieger CH, Mitchell I, Fredrick L, Groothuis JR. The effect of respiratory syncytial virus on subsequent recurrent wheezing in atopic and nonatopic children. J Allergy Clin Immunol 2010;126:256-62.

31. Jafri HS, Chavez-Bueno S, Mejias A, et al. Respiratory syncytial virus induces pneumonia, cytokine response, airway obstruction, and chronic inflammatory infiltrates associated with long-term airway hyperresponsiveness in mice. J Infect Dis 2004;189:1856-65.

32. Mejías A, Chávez-Bueno S, Rios AM, et al. Comparative effects of two neutralizing anti-respiratory syncytial virus (RSV) monoclonal antibodies in the RSV murine model: time versus potency. Antimicrob Agents Chemother 2005;49:4700-7.

33. Schuurhof A, Janssen R, de Groof $\mathrm{H}$ et al. Local interleukin-10 production during respiratory syncytial virus bronchiolitis is associated with post-bronchiolitis wheeze. Respir Res 2011;12:121.

34. Mäkelä MJ, Kanehiro A, Dakhama A, et al. The failure of interleukin-10-deficient mice to develop airway hyperresponsiveness is overcome by respiratory syncytial virus infection in allergen-sensitized/ challenged mice. Am J Respir Crit Care Med 2002;165:824-31.

35. Mäkelä MJ, Kanehiro A, Borish L, et al. IL-10 is necessary for the expression of airway hyperresponsiveness but not pulmonary inflammation after allergic sensitization. Proc Natl Acad Sci U S A 2000; 97:6007-12.

36. Loebbermann J, Schnoeller C, Thornton $\mathrm{H}$, et al. IL-10 regulates viral lung im- munopathology during acute respiratory syncytial virus infection in mice. PLoS One 2012;7(2):e32371.

37. Bermejo-Martin JF, Garcia-Arevalo $\mathrm{MC}$, Alonso A, et al. Persistence of proinflammatory response after severe respiratory syncytial virus disease in children. J Allergy Clin Immunol 2007;119:1547-50.

38. Casalegno JS, Bouscambert-Duchamp $M$, Morfin F, Lina B, Escuret V. Rhinoviruses, $A(H 1 N 1) v$, RVS: the race for hivernal pandemics, France 2009-2010. Euro Surveill 2009;14(44)

39. Linde A, Rotzén-Ostlund M, Zweygberg-Wirgart B, Rubinova S, Brytting M. Does viral interference affect spread of influenza? Euro Surveill 2009;14(40).

40. van der Zalm MM, Uiterwaal CS, de Jong BM, Wilbrink B, van der Ent CK. Viral specimen collection by parents increases response rate in population-based virus studies. J Allergy Clin Immunol 2006;117:955-7.

41. van der Zalm MM, Uiterwaal CS, Wilbrink B, et al. Respiratory pathogens in respiratory tract illnesses during the first year of life: a birth cohort study. Pediatr Infect Dis J 2009;28:472-6.

42. Colin AA, McEvoy C, Castile RG. Respiratory morbidity and lung function in preterm infants of 32 to 36 weeks' gestational age. Pediatrics 2010;126:115-28.

43. Brand PL, Baraldi E, Bisgaard H, et al. Definition, assessment and treatment of wheezing disorders in preschool children: an evidence-based approach. Eur Respir J 2008;32:1096-110.

44. Elphick HE, Sherlock P, Foxall G, et al. Survey of respiratory sounds in infants. Arch Dis Child 2001;84:35-9.

Copyright (@) 2013 Massachusetts Medical Society.

The Journal requires investigators to register their clinical trials in a public trials registry. The members of the International Committee of Medical Journal Editors (ICMJE) will consider most reports of clinical trials for publication only if the trials have been registered.

Current information on requirements and appropriate registries is available at www.icmje.org/faq_clinical.html. 